\title{
Training socio-affective and -cognitive processes
}

Abigail Thompson \& Nikolaus Steinbeis

Division of Psychology and Language Sciences

University College London

26 Bedford Way

London,

WC1H 0AP

Word Count: 7176 words

Key words: Empathy, Compassion, Theory of mind, Prosocial Behaviour book. 


\begin{abstract}
The potential to train social capacities could have wide-ranging positive effects for society, and may be particularly relevant to clinical conditions in which social challenges impact on wellbeing and quality of life. Yet, the study of whether and how social skills can be trained has been neglected until recently. This chapter provides an overview of the most recent studies which have sought to train social abilities across different developmental populations. An overview is first provided of socio-cognitive (Theory of Mind) and socioaffective (Empathy, Compassion) processes, after which studies seeking to enhance these skills are reviewed. Studies are divided into those that directly target the particular skill, or seek to enhance it by targeting an associated function. The neural mechanisms associated with training and impact on prosocial behaviours are highlighted, and methodological implications are discussed throughout. Overall, studies suggest training social capacities may be effective, however further research will be needed to clarify the precise methodological features that lead to training success.
\end{abstract}

This chapter will appear in the book Cognitive Training, on behalf of Springer (estimated print publication date April 2020). The printed version may not exactly replicate the authoritative document published in the Springer book. 


\section{Introduction}

Understanding the emotions, beliefs and desires of others is a core human capacity that enables us to navigate the complex and interwoven social world in which humans are embedded. The potential to train social skills and increase human interpersonal understanding has an almost utopian appeal. A lack of understanding, or caring about the perspectives of others, has been blamed for such wide-ranging and devastating issues as political divide, war, ruthless capitalism and human suffering. Equally, good social abilities ensure increased social connectedness, which in turn is highly predictive of health and well-being (Cornwell and Waite, 2009; Jose, Ryan and Pryor, 2012).

On a more practical level, the ability to train social capacities could improve the lives of individuals who experience day to day challenges due to social difficulties. Autism spectrum conditions have likely been most widely studied in this regard, but notably, challenges with social abilities are inherent to many other clinical conditions including schizophrenia, attention-deficit hyperactivity disorder, conduct disorder and depression, with social challenges affecting wellbeing and quality of life (see deVries and Geurts this volume). It may also confer a number of advantages for professions in which understanding is a day to day aspect of the job (i.e. doctors). In fact, one exciting aspect of the current field is that in recent years researchers have made strides into defining the isolated components of socio-cognitive processes and in particular interpersonal understanding (Singer and Klimecki, 2014). Much is known about training motor (Papale and Hooks, 2018), perceptual (Broadbent, Causer, Williams, \& Ford, 2015; Bediou et al. this volume) and cognitive skills (Blair, 2017; e.g., Guye et al., Rueda et al. this volume), yet whether and how socio-cognitive processes can be trained has been negletcted until recently. The purpose of this chapter is to bring together the most recent advances in the field on training socio-cognitive abilities and behaviors.

\section{This chapter}

Socio-affective and socio-cognitive processes include numerous components. For the purpose of the present review we will cover those that are related to understanding others and prosocial behaviour. This chapter will first provide an overview of socio-cognitive and socio-affective routes to interpersonal understanding, including theory of mind (ToM), empathy and compassion and will then go on to discuss the empirical studies that have been conducted to train these skills. Each of the routes to interpersonal understanding considered are supported by, or associated with, other mechanisms, such as executive functions and language in the case of ToM. For this This chapter will appear in the book Cognitive Training, on behalf of Springer (estimated print publication date April 2020). The printed version may not exactly replicate the authoritative document published in the Springer book. 
reason, this chapter divides the reviewed into studies where the training directly targets the desired social skill, or indirectly targets other abilities and report an outcome on the target social skill.

Whilst training studies have often been conducted with the explicit aim of enhancing a particular social skill, such training can also be seen as a particularly useful tool to manipulate and tap into the underlying mechanisms. Thus, through training, many studies dissect and shed light on the underlying process itself (Hale and Tager-Flusberg, 2003; Lohmann and Tomasello, 2003; Santiesteban, White, et al., 2012). Following the progress of training studies targeting specific components of any given skill, reveals an intriguing history of how researchers have thought about these concepts on the whole.

The plasticity of socio-affective and-cognitive processes is a new field of research. Although the majority of training studies have been conducted in adults, we will discuss developmental mechanisms and integrate developmental literature where possible. As with all cognitive training studies, the outcomes of training in this arena are closely related to methodological factors such as study design (including use of a control group), type and intensity of training, including number of training sessions (see Cochrane and Green, Schmiedek, Könen and Auerswald this volume). Thus, where possible we will seek to discuss these factors in the context of the following questions: is this interpersonal skill trainable? What key mechanisms are involved? What methodological factors appear to be most important in facilitating this?

\section{Socio-cognitive and socio-affective routes to interpersonal understanding}

The way in which we gain understanding of each other can be divided into two relatively distinct routes;

cognitive and affective (Singer, 2006) ${ }^{1}$. This distinction appears to be underpinned by relatively separate neural mechanisms (Shamay-Tsoory, Aharon-Peretz and Perry, 2009; Kanske et al., 2015), a primary distinction being that socio-affective may be considered 'hot' in the sense that they involve limbic regions of the brain whereas socio-cognitive does not, and may be considered 'cold'. These routes develop separately and are largely

\footnotetext{
${ }^{1}$ A note on terminology: Empathy and associated functions have been defined in various ways. For the purposes of the current chapter we have chosen to use an adaptation of the classification system of Singer (2006), which takes advantage of a primary distinction between socio-cognitive and socio-affective abilities, because this distinction appears to be meaningful at a neural level. Some researchers classify experience sharing, mentalising and empathic/pro-social concern as subcomponents of 'empathy' (e.g. Zaki and Ochsner, 2012). These terms relate to empathy, ToM and compassion, as used in the current study.
}

This chapter will appear in the book Cognitive Training, on behalf of Springer (estimated print publication date April 2020). The printed version may not exactly replicate the authoritative document published in the Springer book. 
independent behaviourally although likely both play a role in complex (or real life) social scenarios (Zaki and Ochsner, 2009; Kanske et al., 2016).

\subsection{Socio-cognitive}

We may rationalise about the desires, beliefs and intentions of others, in an effort to explain the causes behind their actions. This is the awareness that other people have different representations and beliefs about the world than we do, and the ability to make assumptions about what these representations may be. Taking on the perspective of another person is a primarily cognitive process, referred to as possessing a ToM (Premack and Woodruff, 1978) or engaging in 'mentalising' (Frith and Frith, 2003). The false belief task is the most common task used to assess this (Wimmer and Perner, 1983; Baron-Cohen, Leslie and Frith, 1985).

\section{Development of ToM}

Although implicit understanding of false beliefs may be present in infancy (Oniski and Baillargeon, 2005; Kovács, Téglás and Endress, 2010), and continues to mature into adolescence (Grazzani and Ornaghi, 2012; Devine and Hughes, 2014), the developmental period between the ages of 3-5 appears to be critical for ToM development (Wellman, Cross and Watson, 2001). Numerous studies report that at the age of 3 children are not able to pass a customary measure of ToM skills, the false belief task, whilst at ages 4 and above, a majority of children are (Wimmer and Perner, 1983; Astington and Gopnik, 1991; Wellman and Lagattuta, 2000); an effect that has been reported across cultures (Liu et al., 2008).

Understanding the possible reasons for this developmental shift in ability has been the focus of many studies over the past twenty years. It is now understood that ToM development is influenced by a wide range of factors including family size (Perner, Ruffman and Leekam, 1994; McAlister and Peterson, 2007), exposure to discussion of mental states and feelings within families (Cutting and Dunn, 1999), engagement in pretend play (Lillard, 2013) and family socioeconomic status (Cutting and Dunn, 1999). Nonetheless, two primary factors have been most dominant: executive functions and language abilities.

\section{Supporting mechanisms - executive functions}

A relationship between ToM and executive functions (EF; Karbach and Kray; Strobach and Schubert this volume) was established by findings that show a correlational nature between their development (Perner and

This chapter will appear in the book Cognitive Training, on behalf of Springer (estimated print publication date April 2020). The printed version may not exactly replicate the authoritative document published in the Springer book. 
Lang, 1999; Perner, Lang and Kloo, 2002; Carlson, Mandell and Williams, 2004). Two prominent theories have been proposed to explain this relationship. Firstly, that ToM tasks depend upon EF abilities, thus, the development of EF are a necessary prerequisite to be able to successfully complete ToM (and that failure on ToM tasks may actually reflect under-developed EF) (Russell, 1997). This is known as the 'expression' account. Secondly, that EF support the development of ToM indirectly, by enabling children to maximise other experiences that support ToM development in day-to-day life, such as social interactions. This is the ‘emergence’ account.

\section{Supporting mechanisms - language}

Similar to the relationship between ToM and EF, early studies identifying a relationship between ToM and language skills reported correlations in their development (Jenkins and Astington, 1996; Hughes and Dunn, 1997; Cutting and Dunn, 1999), and specifically that early language skills predict later ToM abilities, but not the other way around (Astington \& Jenkins, 1999). There are a number of different theories about the relationship, one of which is the conversational hypothesis - that ToM development is supported by discussing mental state terms during conversation (Siegal, 1999; Hutto, 2007). Both EF and language may specifically support explicit but not implicit ToM (Grosse Wiesmann, Friederici, et al., 2017).

\section{Neural mechanisms}

At a neural level, ToM recruits the medial prefrontal cortex, superior temporal sulcus, precuneus and ventral temporo-parietal junction (TPJ) (Adolphs, 2009; Schurz et al., 2014). The TPJ appears to play a critical role potentially underpinning an ability that has been demonstrated to be necessary for cognitive perspective taking self-other distinction - the ability to inhibit and separate one's own response to a situation to that of another person (Saxe, Carey and Kanwisher, 2004; Decety and Lamm, 2007; Santiesteban, Banissy, et al., 2012; Steinbeis, 2016; Grosse Wiesmann, Schreiber, et al., 2017).

\subsection{Socio-affective: empathy and compassion}

In contrast to cognitive routes to understanding, we may feel an instinctive resonance to the plight or suffering of others. This is a reflection of an emotional state and involves an affective processing route. Within this affective route, there are two key social capacities: empathy and compassion.

This chapter will appear in the book Cognitive Training, on behalf of Springer (estimated print publication date April 2020). The printed version may not exactly replicate the authoritative document published in the Springer book. 
Empathy is the sharing of feelings of another, whether positive or negative, whilst maintaining awareness that those feelings are not your own (Eisenberg and Strayer, 1987). Although there are widely recognised social benefits to empathy, in recent years researchers have discussed the potential downsides of empathy. For example, empathic responses are biased to in-group, out-group membership (Lamm, Decety and Singer, 2011) suggesting prejudice, and are sensitive to moral blame (Decety, Echols and Correll, 2010). Furthermore, sharing the negative emotions of another can cause an aversive reaction known as empathic distress, which can lead to avoidance behaviours due to a desire to reduce the negative emotions felt by oneself (Batson, Fultz and Schoenrade, 1987).

In contrast, compassion (also known as empathic concern or sympathy) is characterised as concern for the welfare of others without necessarily feeling what they are feeling (Bloom, 2017). This is associated with positive feelings, a focus on the other person rather than oneself, and motivation to engage in prosocial behaviours such as helping. A key determinant of whether an affective response is compassionate or empathetic, may be self-regulation (Eisenberg et al., 1998; Nancy Eisenberg, Fabes, \& Spinrad, 2006). Failure to regulate one's emotional response may lead to overarousal and empathic distress (Decety, 2010).

\section{Development}

A developmental prerequisite of empathy is emotional contagion; the automatic ability to resonate with the emotions of others, which is present in infants (Heyes, 2018). Empathic responding is present in children as young as two years old (Eisenberg, Fabes and Spinrad, 2006). The emergence of self-other distinction is key for emotional contagion to develop into empathic responding. The role of self-other distinction was demonstrated in a study which reported that 16-24 month old children who passed a self-recognition mirror test were more likely to help an adult who displayed distress in response to a teddy's arm breaking off (Bischof-Köhler, 1994).

\section{Neural mechanisms}

Empathising with another person activates regions of the brain that are also involved when experiencing something oneself, with the degree of activation associated with the degree to which participants also felt negative feelings when observing another in pain (Lamm, Decety and Singer, 2011) and anterior insula activation specifically correlates with empathic concern ratings (Singer et al., 2004). Empathy recruits limbic and paralimbic areas including the anterior insula and anterior cingulate cortex, as well as the dorso-lateral

This chapter will appear in the book Cognitive Training, on behalf of Springer (estimated print publication date April 2020). The printed version may not exactly replicate the authoritative document published in the Springer book. 
prefrontal cortex and supramarginal gyrus (Fan et al., 2011; Kanske et al., 2015). Activation in the anterior insula in particular is modulated by contextual factors such as in-group, out-group membership, and predicts helping behaviour (Hein et al., 2010). In contrast, compassion has a distinct neural signature to that of empathy, specifically recruiting the ventral orbitofrontal cortex, ventral striatum and ventral tegmental area (Klimecki et al., 2013; Singer and Klimecki, 2014). These are regions involved in positive emotions, including maternal and affiliative love, pointing towards the positive role of compassion.

\subsection{Relation to prosocial behaviours}

For training in any social domain to be impactful in a meaningful sense, it must relate to behaviour change in the realm of prosocial behaviours, which includes helping, comforting others in distress, or sharing of resources. The distinction between the different components of social skills, and associated neural systems, is important in the context of cognitive training because they likely lead to distinct outcomes in terms of prosocial behaviour (as discussed above). Many studies report changes in the targeted skill rather than changes in objectively measured social behaviours. Throughout the chapter, we will highlight any studies that do report changes in terms of prosocial behaviour.

\section{Training studies}

\subsection{Training socio-cognitive skills}

The first study to show a successful training effect on ToM was Slaughter and Gopnik (1996). Since then, a wealth of training studies have been conducted making use of a range of different training approaches including social cognition and perspective taking, storytelling enriched with mental states, corrective feedback, role play, and language based interventions such as narrative training and sentential complements. Due to the developmental studies that have shown a relatively robust shift in ToM understanding between the ages of 3 and 4, a majority of training studies targeting ToM have focused on this age group; both for typical development and groups of autistic or hearing impaired children.

A recent meta-analysis (Hofmann et al., 2016) reviewed studies that have aimed to train ToM in children using different approaches including social cognition and perspective taking, language and storytelling based approaches. The authors only included studies that featured a control group and did not exclude clinical conditions such as autism and hearing impairments. 45 studies from 32 papers were included in the final

This chapter will appear in the book Cognitive Training, on behalf of Springer (estimated print publication date April 2020). The printed version may not exactly replicate the authoritative document published in the Springer book. 
analysis. The number of training sessions ranged from 1-32. The authors report a moderately strong effect of ToM training, compared with controls, across studies (Hedges' $g=0.75, C I=0.60-0.89, p<.001$ ). Thus, the overall conclusion is that it is indeed possible to train ToM. However, there are a few important points to note. Firstly, the author's point out that it was not possible to disentangle potential moderator effects, such as the impact of individual differences in language or EF, because many studies do not report these abilities. It also was not possible to parse the training-related or contextual factors that may be most beneficial to training, such as the specific type of training intervention, setting or format of the training. Secondly, none of the included studies provided a long-term measure of effects, therefore it is unknown whether the effects of ToM training last (the longest interval between training and post-test was 13 days).

\section{Studies that indirectly train ToM: Executive functions}

Studies report that children with higher EF skills benefit most from ToM training (Benson et al., 2013; Gao et al., 2019) and that directly training EF leads to improvements in ToM abilities (Kloo and Perner, 2003; Fisher and Happé, 2005). In one study, training on an EF task, the Dimensional Change Card Sorting task lead to increases in performance on a false-belief task in children between the ages of 3-4.7 (Kloo and Perner, 2003). Curiously, training on the false belief task also lead to improvements on the EF task. The authors suggest that this indicates that both tasks tap into similar processes, however, it does not clarify in what way EF and ToM performance are related.

Another study reports that training autistic children on either EF or ToM abilities lead to improvements in ToM abilities in both groups (Fisher and Happé, 2005). Intriguingly, they found that there was a large immediate enhancement of ToM skills in the group trained on ToM abilities, whereas for the group trained on EF, the improvement in ToM skills was most apparent at a later period (measured 6-12 weeks after the intervention). The authors suggest that this may indicate that the ToM training may have a more direct effect, whilst EF training may be indirect, and may lead to the development of other skills (such as set shifting) which, at a later timepoint, they then are able to use to their advantage on ToM tasks. Also, the sample size was very small.

A unique study in adults used training to investigate contrasting theories regarding the role of action imitation in socio-cognitive processes (Santiesteban, White, et al., 2012). They report that training imitation inhibition lead to improvements in performance on a visual perspective taking task. This contrasted with two other training

This chapter will appear in the book Cognitive Training, on behalf of Springer (estimated print publication date April 2020). The printed version may not exactly replicate the authoritative document published in the Springer book. 
groups, one in which participants imitated the actions of another person and another where general inhibition skills were trained. This made it possible to determine that the training effects of the imitation inhibition group were specific to social skills and were not a result of inhibitory control training, per se. This finding provided support for the notion that inhibition of imitation is central to perspective taking (rather than the contrasting theory that imitation facilitates ToM, through activation of the mirror neuron system (Gallese and Goldman, 1998))

\section{Language}

Hale and Tager-Flusberg (2003) tested the hypothesis that ToM development is dependent on language in a training study in which 72 children were divided into three groups; one received ToM training, one received training on sentential complements and a final group (an active control) received training on a different embedded construction - relative clauses. A sentential complement is a grammatical clause which enables "the relativity of belief and knowledge states" (de Villiers, 2000) and has been proposed to be fundamentally involved in ToM skills by enabling us to comprehend how another person may think or feel. The authors report that training in both the ToM and sentential complements groups improved on ToM scores, and the control group did not. This shows that, in line with theory, training on sentential complements improved ToM. However, since both groups improved on ToM scores, this does suggest that the linguistic skills are not a necessary prerequisite.

Lohmann and Tomasello (2003) pointed out that all ToM training studies (including that of Hale \& TagerFlusberg 2003, but also including studies that do not focus on language) include deceptive scenarios. Thus, it cannot be concluded that the effect of training in sentential complements is specifically related to this rather than being exposed to deception. In a well designed study, they compared multiple training groups in order to directly tease out the influence of several factors believed to contribute to ToM. The training groups included: 1 ) exposure to deceptive experience without language (to test whether deceptive experience per se was the driving force), 2) exposure to sentential complements only (without deception), 3) exposure to perspective-shifting discourse only, and 4) a 'full' group which was exposed to both language conditions and deception. They report ToM abilities improved in all groups, apart from the group that did not experience language, suggesting that deceptive experiences alone were not sufficient to lead to ToM improvements. The greatest impact was seen in the 'full' group, suggesting that, whilst training on both sentential complements and narrative discourse

This chapter will appear in the book Cognitive Training, on behalf of Springer (estimated print publication date April 2020). The printed version may not exactly replicate the authoritative document published in the Springer book. 
independently had an impact on ToM abilities, they may have independent effects on ToM and thus, the most effective training course would include both.

Interim summary: training socio-cognitive skills

Overall, these studies demonstrate that socio-cognitive skills are plastic and are amenable to a range of different interventions across a broad age range. This is the case both in typically developing children and children with developmental conditions. The most effective training regime may be multi-faceted, including multiple elements such as narrative, sentential complements and role play. Limitations of this area currently are that studies typically include only small sample sizes (Fisher and Happé, 2005), rarely provide long-term follow up and generally do not report the impact of such training on "real life" measures reflecting social skills, which may be more ecologically valid. Thus, it is unclear whether training improvements have a lasting effect on children's ToM abilities or whether there is transfer to day-to-day life (Ozonoff and Miller, 1995).

\subsection{Training socio-affective skills}

\section{Empathy}

Studies training empathy have focused on improving understanding of what empathy is and improving the ability to identify emotions or take the perspective of others, through a range of lecture-based (didactic) and experiential approaches (Lam, Kolomitro and Aamparambil, 2011). Experiential approaches include role-play and imagination activities, which aim to foster empathy by providing an insight into the experience of another person. For example, studies have simulated hallucinations to foster empathy for mental health patients (Bunn and Terpstra, 2009), and used virtual reality to give participants the experience of visiting a refugee camp, which lead to increased empathy for refugees (Schutte and Stilinović, 2017).

Reviews of empathy training conclude that it is possible to train empathy across different populations including physicians, undergraduate medical students, therapists, nurses and couples (Brunero, Lamont and Coates, 2010; Lam, Kolomitro and Aamparambil, 2011; Batt-Rawden et al., 2013; Rogge et al., 2013). A meta-analysis of 18 randomised controlled trials supported this conclusion, reporting a moderate overall effect of empathy training (Hedges' $\mathrm{g}=0.63, \mathrm{CI}=0.39-0.87, \mathrm{p}<.001$ ) (van Berkhout and Malouff, 2016). Training effects were significantly moderated by the type of trainee (training involving health professionals and university students was effective, but for the other groups it was not), the offer of compensation, and scope and objectivity of

This chapter will appear in the book Cognitive Training, on behalf of Springer (estimated print publication date April 2020). The printed version may not exactly replicate the authoritative document published in the Springer book. 
outcome measures (objective measures were associated with more effective empathy training compared to self report measures).

This suggests empathy to be trainable, however it is unclear what exactly is being trained. Conceptualisations of empathy and how to measure it vary considerably from study to study (Lam, Kolomitro and Aamparambil, 2011). For example, all of the studies reviewed in van Berkhout and Malouff (2016) include a 'cognitive empathy' element, which emphasises being able to take the perspective of another person, and may be considered to be a socio-cognitive training approach. This may suggest it is possible, on an intellectual level, to gain understanding of what empathy is and how to take the perspective of another. Less is known about whether it is possible to alter the affective, experience-sharing component of empathy (Lam, Kolomitro and Aamparambil, 2011), or how improvements in empathy understanding relate to behaviour change in more naturalistic settings, since this is also influenced by motivational and contextual factors (Weisz and Zaki, 2017).

\section{Compassion}

In addition to training empathy, in recent years a number of training studies have specifically targeted compassion. Short-term prosocial effects of compassion induction had been demonstrated previously (Batson $e t$ al., 2007), however the first study to report the potential longer term (i.e. spanning multiple days) prosocial effects of training compassion was reported by Leiberg, Klimecki, \& Singer (2011). They report increased prosocial behaviours 2-5 days after a day workshop that taught a Buddhist contemplative technique specifically designed to enhance compassion, compared with a group who received a workshop on memory training. Prosocial behaviours were assessed using a novel game to test helping behaviours, the Zurich Prosocial Game, which enables separate investigation of the influence of reciprocity, cost and distress cues on helping behavior. The number of hours of compassion training related to helping in the no-reciprocity trials but not on the reciprocity trails. This may suggest compassion training specifically enhances prosocial behaviours when there is no opportunity for reciprocity, which contrasts with norm-based (i.e. "cold”, reason-driven) helping (Singer and Steinbeis, 2009). Overall, this study was the first to suggest it is possible to impact trait-level compassion.

This finding was further supported by a subsequent study (Weng et al., 2013) which reported that participants who received meditation based compassion training gave more funds in an anonymous online game, in comparison to a group who received training in emotional reappraisal. The game was an economic decision

This chapter will appear in the book Cognitive Training, on behalf of Springer (estimated print publication date April 2020). The printed version may not exactly replicate the authoritative document published in the Springer book. 
making game, in which individuals first saw another individual (the 'dictator') transfer an unfair amount of money to another person. In this way, the game specifically tapped into unfairness norms. Using an ecologically valid design, another study compared compassion and mindfulness training (Condon et al., 2013). After 8 weeks of training, participants visited the lab in order to complete a battery of tests. In the waiting room before entering the lab, an actor appeared with crutches and a walking boot, appearing to be visibly wincing. Without the knowledge of the participants, the experimenters noted whether the participant offered their seat. They found that both meditation groups offered their seat more often than the non-meditation control group and there was no difference between the compassion or mindfulness meditation groups. This suggests that it cannot be determined whether the prosocial effects of compassion training in the early studies of Leiberg et al. (2011) and Weng et al. (2013) are specific to compassion, or a general product of meditation, since they both used nonmeditation controls.

More recent studies were designed in order to specifically answer these questions. The ReSource Project is central to this (Singer et al., 2016). This is a large-scale ( $\mathrm{N}=323$ healthy adult participants) training study, investigating the specificity of training effects across three distinct training modules which each used different meditation techniques. The training modules were: 'presence', 'affect' and 'perspective'. These were based on mindfulness, fostering compassion, and developing perspective taking abilities, respectively. Participants were assigned to one of the three active training groups or to a retest cohort, which acted as a non-active control group. All groups were matched on a range of variables including age, gender, IQ, income, marital status and personality traits. Two of the active training groups experienced the three training modules but in different orders, running consecutively one after another in 3-month blocks. The third active training group received only 'affect' training. Thus, in addition to the non-active control, the training groups were used as active controls for each other. This well controlled study design enabled direct comparison across the different training types, specifically enabling the investigation of differential effects of training targeting mindfulness, compassion and perspective taking, and their subsequent impact on both behaviour and neural substrates.

The project reported specificity of behavioural outcomes for each module. 'Affect' training lead to increased self-reported compassion and gains in ToM were achieved by the module targeting perspective-taking (Trautwein et al., 2017). The 'presence' module, based on mindfulness techniques that do not have an affective component, did not lead to increases in either compassion or ToM. There were also differential effects of the This chapter will appear in the book Cognitive Training, on behalf of Springer (estimated print publication date April 2020). The printed version may not exactly replicate the authoritative document published in the Springer book. 
distinct training types on sub-components of prosocial behaviour (Böckler et al., 2018). Altruistic behaviours, measured by a range of behavioural tasks such as donations and helping, were only increased by targeting compassion training ('affect' module), suggesting a specific impact of compassion training on prosocial behaviours. In contrast, self-reported prosociality increased across all active training groups, suggesting meditation training in general lead to increased self-reported prosocial behaviour, despite changes in measured prosociality only occuring in the 'affect' group. This is pertinent in the context of other compassion training studies using self-report measures as their primary outcome.

\section{Neural effects of training}

A current debate within the field is whether compassion based meditation training facilitates behavioural effects due to changes in affective or cognitive systems (Dahl, Lutz and Davidson, 2016; Engen and Singer, 2016). Early neuroimaging studies were equivocal, reporting compassion meditation training to be associated with changes in either reward and limbic systems, including the VTA, mOFC, pallidum and putamen (Klimecki et al., 2013), and cognitive regions involved in mentalising, including dlPFC, dmPFC and inferior parietal lobule (Mascaro et al., 2013; Weng et al., 2013).

The ReSource project studies report specificity at a neural level. The behavioural effects of the 'affect' and 'perspective' modules were associated with changes in cortical thickness across the brain across spatially segregated networks (Valk et al., 2017), which overlapped with socio-affective and socio-cognitive networks, respectively, which also mapped onto functional networks. A recent study compared compassion training with two other groups: a placebo group, who were told they were inhaling oxytocin, and a 'familiarity' group. By comparing these different groups it was possible for the authors to disentangle demand characteristics and placebo effects (Kreplin, Farias and Brazil, 2018). They reported increased responses to suffering in the mOFC in a compassion training group compared with two other groups and also in the NAcc compared with the familiarity group. This provides support for the notion and previous studies that have suggested that compassion meditation acts via role for limbic/motivational/affective pathways (Klimecki et al., 2013).

\section{Interim discussion: socio-affective training}

Overall, studies suggest it is possible to improve individuals self-report ratings of empathy and compassion and that prosocial behaviours, including helping and sharing, may increase with compassion training. There may be

This chapter will appear in the book Cognitive Training, on behalf of Springer (estimated print publication date April 2020). The printed version may not exactly replicate the authoritative document published in the Springer book. 
a dissociation between self-reported measures of increases in prosociality and actual behaviours (Böckler et al., 2018; Ashar et al., 2019). Further, the degree to which individuals actually experienced a change in their own affective experience as opposed to simply learning about it, is unclear. This has interesting implications for the potential application of such training paradigms for clinical or applied groups (such as bullying or conduct disorder); as individuals may gain understanding of what empathy and compassion are and rate themselves as more empathetic, but this may not lead to behaviour change.

\section{Overall conclusions}

This chapter summarises the studies that have been conducted targeting socio-cognitive and socio-affective processes. Whilst studies suggest that training may be effective in both of these arenas, the precise methodological factors that facilitate learning are largely unmapped (see also Cochrane and Green this volume). Additionally, the long-term effects and 'real world' effects of such training are largely unknown. Further, while some efforts have been made to train these skills in developmental populations, more research is needed to see how the effectiveness of training socio-cognitive and -affective processes might change with age.

This chapter will appear in the book Cognitive Training, on behalf of Springer (estimated print publication date April 2020). The printed version may not exactly replicate the authoritative document published in the Springer book. 


\section{References:}

Adolphs, R. (2009) 'The Social Brain: Neural Basis of Social Knowledge', Annual Review of Psychology. doi: 10.1146/annurev.psych.60.110707.163514.

Ashar, Y. K. et al. (2019) 'No Title', (303), pp. 1-26.

Astington, J. W. and Gopnik, A. (1991) 'Theoretical explanations of children's understanding of the mind', British Journal of Developmental Psychology. doi: 10.1111/j.2044-835x.1991.tb00859.x.

Astington, J. W. and Jenkins, J. M. (1999) 'A longitudinal study of the relation between language and theory-ofmind development.', Developmental psychology. doi: 10.1037/0012-1649.35.5.1311.

Baron-Cohen, S., Leslie, A. M. and Frith, U. (1985) 'Does the autistic child have a "theory of mind"?', Cognition. doi: 10.1016/0010-0277(85)90022-8.

Batson, C. D. et al. (2007) 'An Additional Antecedent of Empathic Concern: Valuing the Welfare of the Person in Need', Journal of Personality and Social Psychology. doi: 10.1037/0022-3514.93.1.65.

Batson, C. D., Fultz, J. and Schoenrade, P. A. (1987) 'Distress and Empathy: Two Qualitatively Distinct Vicarious Emotions with Different Motivational Consequences', Journal of Personality. doi: 10.1111/j.14676494.1987.tb00426.x.

Batt-Rawden, S. A. et al. (2013) 'Teaching empathy to medical students: An updated, systematic review', Academic Medicine doi: 10.1097/ACM.0b013e318299f3e3.

Benson, J. E. et al. (2013) 'Individual differences in executive functioning predict preschoolers' improvement from theory-of-mind training', Developmental Psychology, 49(9), pp. 1615-1627. doi: 10.1037/a0031056. van Berkhout, E. T. and Malouff, J. M. (2016) 'The efficacy of empathy training: A meta-analysis of randomized controlled trials', Journal of Counseling Psychology, 63(1), pp. 32-41. doi: 10.1037/cou0000093. Bischof-Köhler, D. (1994) 'Self object and interpersonal emotions. Identification of own mirror image, empathy and prosocial behavior in the 2nd year of life', Zeitschrift für Psychologie mit Zeitschrift für angewandte Psychologie.

Blair, C. (2017) 'Educating executive function', Wiley Interdisciplinary Reviews: Cognitive Science. doi: 10.1002/wcs.1403.

Bloom, P. (2017) 'Empathy and Its Discontents', Trends in Cognitive Sciences. Elsevier Ltd, 21(1), pp. $24-31$. doi: 10.1016/j.tics.2016.11.004.

Böckler, A. et al. (2018) 'Distinct mental trainings differentially affect altruistically motivated, norm motivated, and self-reported prosocial behaviour', Scientific Reports, 8(1), pp. 1-14. doi: 10.1038/s41598-018-31813-8. Broadbent, D. P. et al. (2015) 'Perceptual-cognitive skill training and its transfer to expert performance in the field: Future research directions', European Journal of Sport Science. doi: 10.1080/17461391.2014.957727. Brunero, S., Lamont, S. and Coates, M. (2010) 'A review of empathy education in nursing', Nursing Inquiry. doi: 10.1111/j.1440-1800.2009.00482.x.

Bunn, W. and Terpstra, J. (2009) 'Cultivating empathy for the mentally ill using simulated auditory hallucinations’, Academic Psychiatry. doi: 10.1176/appi.ap.33.6.457.

Carlson, S. M., Mandell, D. J. and Williams, L. (2004) 'Executive function and theory of mind: Stability and prediction from ages 2 to 3', Developmental Psychology, 40(6), pp. 1105-1122. doi: 10.1037/0012-

1649.40.6.1105.

Condon, P. et al. (2013) 'Meditation Increases Compassionate Responses to Suffering', Psychological Science, 24(10), pp. 2125-2127. doi: 10.1177/0956797613485603.

Cornwell, E. Y. and Waite, L. J. (2009) 'Social disconnectedness, perceived isolation, and health among older adults', Journal of Health and Social Behavior. doi: 10.1177/002214650905000103.

Cutting, A. L. and Dunn, J. (1999) 'Theory of Mind, emotion understanding, language, and family background: Individual differences and interrelations', Child Development. doi: 10.1111/1467-8624.00061.

Dahl, C. J., Lutz, A. and Davidson, R. J. (2016) 'Cognitive Processes Are Central in Compassion Meditation', Trends in Cognitive Sciences. doi: 10.1016/j.tics.2015.12.005.

Decety, J. (2010) 'The neurodevelopment of empathy in humans', Developmental Neuroscience, 32(4), pp. 257-267. doi: 10.1159/000317771.

Decety, J., Echols, S. and Correll, J. (2010) 'The blame game: The effect of responsibility and social stigma on empathy for pain', Journal of Cognitive Neuroscience, 22(5), pp. 985-997. doi: 10.1162/jocn.2009.21266.

Decety, J. and Lamm, C. (2007) 'The role of the right temporoparietal junction in social interaction: How lowlevel computational processes contribute to meta-cognition', Neuroscientist. doi: 10.1177/1073858407304654. Devine, R. T. and Hughes, C. (2014) 'Relations between false belief understanding and executive function in early childhood: A meta-analysis', Child Development. doi: 10.1111/cdev.12237.

Eisenberg, N. et al. (1998) 'Contemporaneous and longitudinal prediction of children's sympathy from dispositional regulation and emotionality.', Developmental psychology. doi: 10.1037/0012-1649.34.5.910. Eisenberg, N., Fabes, R. A. and Spinrad, T. L. (2006) Social, emotional, and personality development,

This chapter will appear in the book Cognitive Training, on behalf of Springer (estimated print publication date April 2020). The printed version may not exactly replicate the authoritative document published in the Springer book. 
Handbook of child psychology: Vol. 3, (6th ed.). doi: 10.1002/9780470147658.chpsy0311.

Eisenberg, N. and Strayer, J. (1987) 'Critical issues in the study of empathy.', in Empathy and its development. Engen, H. G. and Singer, T. (2016) 'Affect and Motivation Are Critical in Constructive Meditation', Trends in Cognitive Sciences. doi: 10.1016/j.tics.2015.11.004.

Fan, Y. et al. (2011) 'Is there a core neural network in empathy? An fMRI based quantitative meta-analysis', Neuroscience and Biobehavioral Reviews. doi: 10.1016/j.neubiorev.2010.10.009.

Fisher, N. and Happé, F. (2005) 'A training study of theory of mind and executive function in children with autistic spectrum disorders', Journal of Autism and Developmental Disorders, 35(6), pp. 757-771. doi: 10.1007/s10803-005-0022-9.

Frith, U. and Frith, C. D. (2003) 'Development and neurophysiology of mentalizing', Philosophical Transactions of the Royal Society B: Biological Sciences. doi: 10.1098/rstb.2002.1218.

Gallese, V. and Goldman, A. (1998) 'Mirror neurons and the simulation theory of mind-reading', Trends in Cognitive Sciences. doi: 10.1016/S1364-6613(98)01262-5.

Gao, Q. et al. (2019) 'Does executive function influence the development of theory of mind in elementary students?', Current Psychology. Current Psychology. doi: 10.1007/s12144-018-0107-1.

Grazzani, I. and Ornaghi, V. (2012) 'How do use and comprehension of mental-state language relate to theory of mind in middle childhood?', Cognitive Development. doi: 10.1016/j.cogdev.2012.03.002.

Grosse Wiesmann, C., Friederici, A. D., et al. (2017) 'Implicit and explicit false belief development in preschool children', Developmental Science. doi: 10.1111/desc.12445.

Grosse Wiesmann, C., Schreiber, J., et al. (2017) 'White matter maturation is associated with the emergence of Theory of Mind in early childhood', Nature Communications. Nature Publishing Group, 8, pp. 1-10. doi: $10.1038 /$ ncomms 14692 .

Hale, C. M. and Tager-Flusberg, H. (2003) 'The influence of language on theory of mind: A training study', Developmental Science, 6(3), pp. 346-359. doi: 10.1111/1467-7687.00289.

Hein, G. et al. (2010) 'Neural responses to ingroup and outgroup members' suffering predict individual differences in costly helping', Neuron. doi: 10.1016/j.neuron.2010.09.003.

Heyes, C. (2018) 'Empathy is not in our genes', Neuroscience and Biobehavioral Reviews. Elsevier, 95(November), pp. 499-507. doi: 10.1016/j.neubiorev.2018.11.001.

Hofmann, S. G. et al. (2016) 'Training children's theory-of-mind: A meta-analysis of controlled studies', Cognition. Elsevier B.V., 150, pp. 200-212. doi: 10.1016/j.cognition.2016.01.006.

Hughes, C. and Dunn, J. (1997) “"Pretend you didn't know": Preschoolers' talk about mental states in pretend play', Cognitive Development.

Hutto, D. D. (2007) 'Narrative and understanding persons', in Narrative and Understanding Persons: Royal Institute of Philosophy Supplement: 60. doi: 10.1017/CBO9780511627903.002.

Jenkins, J. M. and Astington, J. W. (1996) 'Cognitive factors and family structure associated with theory of mind development in young children', Developmental Psychology. doi: 10.1037/0012-1649.32.1.70.

Jose, P. E., Ryan, N. and Pryor, J. (2012) 'Does Social Connectedness Promote a Greater Sense of Well-Being in Adolescence Over Time?', Journal of Research on Adolescence. doi: 10.1111/j.1532-7795.2012.00783.x. Kanske, P. et al. (2015) 'Dissecting the social brain: Introducing the EmpaToM to reveal distinct neural networks and brain-behavior relations for empathy and Theory of Mind', NeuroImage. Elsevier Inc., 122, pp. 619. doi: 10.1016/j.neuroimage.2015.07.082.

Kanske, P. et al. (2016) 'Are strong empathizers better mentalizers? Evidence for independence and interaction between the routes of social cognition', Social Cognitive and Affective Neuroscience. doi:

$10.1093 / \mathrm{scan} / \mathrm{nsw} 052$.

Klimecki, O. M. et al. (2013) 'Differential pattern of functional brain plasticity after compassion and empathy training', Social Cognitive and Affective Neuroscience, 9(6), pp. 873-879. doi: 10.1093/scan/nst060.

Kloo, D. and Perner, J. (2003) 'Training Transfer Between Card Sorting and False Belief Understanding: Helping Children Apply Conflicting Descriptions', Child Development, 74(6), pp. 1823-1839. doi: 10.1046/j.1467-8624.2003.00640.x.

Kovács, Á. M., Téglás, E. and Endress, A. D. (2010) 'The social sense: Susceptibility to others' beliefs in human infants and adults', Science. doi: 10.1126/science.1190792.

Kreplin, U., Farias, M. and Brazil, I. A. (2018) 'The limited prosocial effects of meditation: A systematic review and meta-analysis', Scientific Reports. Springer US, 8(1), pp. 1-10. doi: 10.1038/s41598-018-20299-z.

Lam, T. C. M., Kolomitro, K. and Aamparambil, F. C. (2011) 'Empathy Training: Methods, Evaluation Practices, and Validity', Journal of Multidisciplinary Evaluation, 7(16), pp. 162-200.

Lamm, C., Decety, J. and Singer, T. (2011) 'Meta-analytic evidence for common and distinct neural networks associated with directly experienced pain and empathy for pain', NeuroImage. doi:

10.1016/j.neuroimage.2010.10.014.

Leiberg, S., Klimecki, O. and Singer, T. (2011) 'Short-term compassion training increases prosocial behavior in

This chapter will appear in the book Cognitive Training, on behalf of Springer (estimated print publication date April 2020). The printed version may not exactly replicate the authoritative document published in the Springer book. 
a newly developed prosocial game', PLoS ONE, 6(3). doi: 10.1371/journal.pone.0017798.

Lillard, A. S. (2013) 'Playful learning and Montessori education', American Journal of Play.

Liu, D. et al. (2008) 'Theory of Mind Development in Chinese Children: A Meta-Analysis of False-Belief

Understanding Across Cultures and Languages', Developmental Psychology. doi: 10.1037/0012-1649.44.2.523.

Lohmann, H. and Tomasello, M. (2003) 'The Role of Language in the Development of False Belief

Understanding: A Training Study', Child Development. doi: 10.1111/1467-8624.00597.

Mascaro, J. S. et al. (2013) 'Compassion meditation enhances empathic accuracy and related neural activity', Social Cognitive and Affective Neuroscience, 8(1), pp. 48-55. doi: 10.1093/scan/nss095.

McAlister, A. and Peterson, C. (2007) 'A longitudinal study of child siblings and theory of mind development', Cognitive Development. doi: 10.1016/j.cogdev.2006.10.009.

Oniski, K. K. and Baillargeon, R. (2005) 'Do 15-month-old infants understand false beliefs?', Science. doi: 10.1126/science.1107621.

Ozonoff, S. and Miller, J. N. (1995) 'Teaching theory of mind: A new approach to social skills training for individuals with autism', Journal of Autism and Developmental Disorders. doi: 10.1007/BF02179376.

Papale, A. E. and Hooks, B. M. (2018) 'Circuit changes in motor cortex during motor skill learning',

Neuroscience. doi: 10.1016/j.neuroscience.2017.09.010.

Perner, J. and Lang, B. (1999) 'Development of theory of mind and executive control', Trends in Cognitive Sciences. doi: 10.1016/S1364-6613(99)01362-5.

Perner, J., Lang, B. and Kloo, D. (2002) 'Theory of mind and self-control: More than a common problem of inhibition', Child Development. doi: 10.1111/1467-8624.00436.

Perner, J., Ruffman, T. and Leekam, S. R. (1994) 'Theory of Mind Is Contagious: You Catch It from Your Sibs', Child Development. doi: 10.1111/j.1467-8624.1994.tb00814.x.

Premack, D. and Woodruff, G. (1978) 'Does the chimpanzee have a theory of mind?', Behavioral and Brain Sciences. doi: 10.1017/S0140525X00076512.

Rogge, R. D. et al. (2013) 'Is skills training necessary for the primary prevention of marital distress and dissolution? A 3-year experimental study of three interventions', Journal of Consulting and Clinical Psychology. doi: 10.1037/a0034209.

Russell, J. (1997) 'How executive disorders can bring about an inadequate "theory of mind", in Autism as an Executive Disorder.

Santiesteban, I., Banissy, M. J., et al. (2012) 'Enhancing social ability by stimulating right temporoparietal junction', Current Biology. doi: 10.1016/j.cub.2012.10.018.

Santiesteban, I., White, S., et al. (2012) 'Training social cognition: From imitation to Theory of Mind', Cognition. Elsevier B.V., 122(2), pp. 228-235. doi: 10.1016/j.cognition.2011.11.004.

Saxe, R., Carey, S. and Kanwisher, N. (2004) 'Understanding Other Minds: Linking Developmental Psychology and Functional Neuroimaging', Annual Review of Psychology. doi: 10.1146/annurev.psych.55.090902.142044.

Schurz, M. et al. (2014) 'Fractionating theory of mind: A meta-analysis of functional brain imaging studies', Neuroscience and Biobehavioral Reviews. doi: 10.1016/j.neubiorev.2014.01.009.

Schutte, N. S. and Stilinović, E. J. (2017) 'Facilitating empathy through virtual reality', Motivation and Emotion. Springer US, 41(6), pp. 708-712. doi: 10.1007/s11031-017-9641-7.

Shamay-Tsoory, S. G., Aharon-Peretz, J. and Perry, D. (2009) 'Two systems for empathy: A double dissociation between emotional and cognitive empathy in inferior frontal gyrus versus ventromedial prefrontal lesions',

Brain. doi: 10.1093/brain/awn279.

Siegal, M. (1999) 'Language and thought: the fundamental significance of conversational awareness for cognitive development', Developmental Science. doi: 10.1111/1467-7687.00048.

Singer, T. et al. (2004) 'Empathy for Pain Involves the Affective but not Sensory Components of Pain', Science. doi: $10.1126 /$ science. 1093535 .

Singer, T. (2006) 'The neuronal basis and ontogeny of empathy and mind reading: Review of literature and implications for future research', Neuroscience and Biobehavioral Reviews, 30(6), pp. 855-863. doi:

10.1016/j.neubiorev.2006.06.011.

Singer, T. et al. (2016) 'The ReSource Project.', Background, design, samples and measurements.

Singer, T. and Klimecki, O. M. (2014) 'Empathy and compassion', Current Biology. Elsevier Ltd, 24(18), pp. R875-R878. doi: 10.1016/j.cub.2014.06.054.

Singer, T. and Steinbeis, N. (2009) 'Differential roles of fairness- and compassion-based motivations for cooperation, defection, and punishment', Annals of the New York Academy of Sciences, 1167, pp. 41-50. doi: 10.1111/j.1749-6632.2009.04733.x.

Slaughter, V. and Gopnik, A. (1996) 'Conceptual Coherence in the Child's Theory of Mind: Training Children to Understand Belief', Child Development. doi: 10.1111/j.1467-8624.1996.tb01898.x.

Steinbeis, N. (2016) 'The role of self-other distinction in understanding others' mental and emotional states: Neurocognitive mechanisms in children and adults', Philosophical Transactions of the Royal Society B:

This chapter will appear in the book Cognitive Training, on behalf of Springer (estimated print publication date April 2020). The printed version may not exactly replicate the authoritative document published in the Springer book. 
Biological Sciences. doi: 10.1098/rstb.2015.0074.

Trautwein, F.-M. et al. (2017) 'Differential Benefits of Mental Training Types for Attention, Compassion, and Theory of Mind', Cognition. Elsevier, 194(August 2019), pp. 1-40. doi: 10.1016/j.cognition.2019.104039.

Valk, S. L. et al. (2017) 'Structural plasticity of the social brain: Differential change after socio-affective and cognitive mental training', Science Advances, 3(10), pp. 1-12. doi: 10.1126/sciadv.1700489.

de Villiers, J. (2000) 'Language and theory of mind: what are the developmental relationships.', pp. 83-123.

Weisz, E. and Zaki, J. (2017) 'Empathy-Building Interventions', in Oxford Handbook of Compassion Science. doi: 10.1093/oxfordhb/9780190464684.013.16.

Wellman, H. M., Cross, D. and Watson, J. (2001) 'Meta-analysis of theory-of-mind development: The truth about false belief', Child Development. doi: 10.1111/1467-8624.00304.

Wellman, H. M. and Lagattuta, K. H. (2000) 'Developing understandings of mind.', Understanding other minds: Perspectives from developmental cognitive neuroscience (2nd ed.).

Weng, H. Y. et al. (2013) 'Compassion Training Alters Altruism and Neural Responses to Suffering', Psychological Science, 24(7), pp. 1171-1180. doi: 10.1177/0956797612469537.

Wimmer, H. and Perner, J. (1983) 'Beliefs about beliefs: Representation and constraining function of wrong beliefs in young children's understanding of deception', Cognition. doi: 10.1016/0010-0277(83)90004-5.

Zaki, J. and Ochsner, K. (2009) 'The need for a cognitive neuroscience of naturalistic social cognition', in Annals of the New York Academy of Sciences. doi: 10.1111/j.1749-6632.2009.04601.x.

Zaki, J. and Ochsner, K. (2012) 'The neuroscience of empathy: Progress, pitfalls and promise', Nature Neuroscience. doi: 10.1038/nn.3085.

This chapter will appear in the book Cognitive Training, on behalf of Springer (estimated print publication date April 2020). The printed version may not exactly replicate the authoritative document published in the Springer book. 